\title{
Precise detection of the germinomatous component of intracranial germ cell tumors of the basal ganglia and thalamus using placental alkaline phosphatase in cerebrospinal fluid
}

\section{Kentaro Chiba}

Tokyo Women's Medical University

Yasuo Aihara ( $\square$ yaihara@twmu.ac.jp)

Tokyo Women's Medical University Hospital https://orcid.org/0000-0002-4837-6248

Takakazu Kawamata

Tokyo Women's Medical University

\section{Research Article}

Keywords: basal ganglia, thalamus, PLAP, biopsy

Posted Date: February 15th, 2021

DOI: https://doi.org/10.21203/rs.3.rs-225462/v1

License: (9) (1) This work is licensed under a Creative Commons Attribution 4.0 International License. Read Full License

Version of Record: A version of this preprint was published at Journal of Neuro-Oncology on February 25th, 2021. See the published version at https://doi.org/10.1007/s11060-021-03715-9. 


\section{Abstract}

Purpose: The disadvantages of biopsy for lesions in the basal ganglia and thalamus include a risk of various complications, difficulty in selecting the target tissue in some cases due to indistinct neuroimaging findings and limited availability of sample tissue. Placental alkaline phosphatase (PLAP) plays a decisive role in the diagnosis and management of intracranial germ cell tumors (IGCTs) in the basal ganglia and thalamus. The present study aimed to demonstrate the ability, specificity, and optimal use of PLAP values obtained from cerebrospinal fluid (CSF).

Methods: Twenty patients with lesions in the basal ganglia and thalamus were enrolled in this study: 11 had IGCTs and 9 had non-IGCTs. The values of PLAP and other established tumor markers in the CSF were measured in all patients before treatment.

Results: The mean follow-up period was 76.0 months (range, 3-168) for all lesions. PLAP was elevated in all 11 patients with IGCTs in the basal ganglia or thalamus, whereas none of the patients with non-IGCT exhibited elevated PLAP. Thus, the sensitivity and specificity of PLAP were both $100 \%$.

Conclusion: Our data demonstrated that the PLAP value can specifically identify the germinomatous component even in cases of IGCTs in the basal ganglia or thalamus with high sensitivity and specificity. PLAP is undoubtedly beneficial for the safe and timely detection of the germinomatous component of IGCTs in the basal ganglia and thalamus, because reliance on PLAP measurement enables us to avoid invasive surgical procedures and facilitates the prompt initiation of chemoradiation therapy.

\section{Introduction}

Lesions in the basal ganglia and thalamus have various origins such as tumors (i.e., gliomas, intracranial germ cell tumors [IGCTs], embryonal tumors with multilayered rosettes, lymphomas, etc.), vascular disease, and degenerative disorders (i.e., multiple sclerosis [MS], neuromyelitis optica [NMO], acute disseminated encephalomyelitis [ADEM], etc.), among others [1-5]. The treatment differs for each condition [6]. For instance, surgical resection, endovascular treatment, or stereotactic radiosurgery can be effective treatment modalities for vascular disease, while steroid therapy is used for degenerative disorders. The management of tumors is based on the World Health Organization (WHO) classification of tumors, which usually requires an accurate histopathological diagnosis. However, tumors of the basal ganglia and thalamus are less amenable to surgical resection owing to their deep-seated and functionally important location [7]. Thus, stereotactic biopsy is generally performed for obtaining tumor samples for histopathological analysis [8]. Stereotactic biopsy is a well-established procedure and is considered relatively safe, although the morbidity of this procedure for basal ganglionic and thalamic lesions is reportedly higher than that for lesions in other intracranial regions [9,8]. Neuroimaging was therefore studied in detail as an alternative to stereotactic biopsy, but unfortunately yielded indecisive results. In contrast, cerebrospinal fluid (CSF) analysis are relatively reliable when specific items or tumor markers are elevated, as in the case of degenerative disorders and IGCTs [1]. CSF tumor markers such as human chorionic gonadotropin (HCG), HCG-beta, and alpha-fetoprotein (AFP) are currently used routinely for differentiating IGCTs from other tumors [10]. However, these tumor markers can detect only a limited subset of IGCT components [11]. For instance, pure germinoma, the most common histological type of IGCT, presents with elevation of these tumor markers only occasionally, which has greatly increased the demand for a specific tumor marker for germinomas.

We have advocated the use of CSF PLAP measurements for the diagnosis of germinomas [12-14]. The measurement of PLAP is useful not only for the diagnosis of pure germinomas but also for detecting the germinomatous component within mixed germ cell tumors because it is a good indicator of the proportion of the germinomatous component $[12,13,15]$. However, we have been concerned with whether the value of PLAP in the CSF can truly reflect the existence of germinomas located in the basal ganglia or thalamus, since these tumors are sometimes far from any ventricle, unlike IGCTs in typical location such as the suprasellar or pineal regions.

The present study aimed to clarify the diagnostic capabilities of this marker and the optimal use of CSF PLAP value over the clinical course, by comparing 11 cases of basal ganglionic and thalamic IGCTs with 9 cases of non-germ cell tumor.

\section{Methods}

Twenty consecutive patients with lesions in the basal ganglia or thalamus who were treated at our hospital between 2005 and 2020 were enrolled in this case series study. Patients with vascular disease (i.e., cavernoma, arteriovenous malformation, etc.) confirmed by threedimensional computed tomography, angiography, or other specific magnetic resonance imaging (MRI) modalities, were excluded. The value of PLAP in the CSF was measured for all patients (Table 1). Eleven patients were diagnosed with IGCT; of these, 4 were diagnosed with germ cell tumor based on elevated PLAP levels in the CSF and/or other CSF tumor markers, including HCG, HCG-beta, and AFP, without obtaining any surgical specimen (Table 1). We set the cut-off value for CSF PLAP at $8 \mathrm{pg} / \mathrm{mL}$ [12]. For technical reasons, this is the minimum limiting value for precise detection by chemiluminescent enzyme immunoassay, since the assay plateaus in sensitivity after $8 \mathrm{pg} / \mathrm{mL}$. At least $1 \mathrm{~mL}$ of pure

Page 2/11 
CSF free of blood contamination is required to evaluate PLAP, for this item alone. We administered adjuvant therapy as a first-line treatment, and subsequently evaluated the efficacy of treatment if the elevation in PLAP levels exceeded $8 \mathrm{pg} / \mathrm{mL}$. The remaining 7 patients underwent biopsy; of these, 3 underwent stereotactic biopsy, 2 underwent endoscopic biopsy in conjunction with endoscopic third ventriculostomy (ETV), and 2 underwent craniotomy (Table 1). Nine patients were diagnosed with non-IGCTs; of these, 4 underwent stereotactic biopsy and 5 underwent tumor resection (Table 1). CSF was collected from all patients, either with ETV from the ventricle before treatment or using lumbar aspiration, depending on the priority for controlling hydrocephalus. Table 1 summarizes the values of the tumor markers in the 20 patients included in this study. The treatment strategy varied with the diagnosis.

\section{Histological diagnosis}

All tumor cases were classified per the WHO classification of tumors of the central nervous system (2016) using standard histopathological and immunohistochemical examinations, conducted by two experienced neuropathologists. Immunohistochemical examinations were conducted on formalin-fixed paraffin-embedded tissue sections using the ChemMate ENVISION kit (Dako Japan, Tokyo, Japan).

\section{Results}

\section{Clinical characteristics, treatment, and outcomes of 20 patients with lesions in the basal ganglia or thalamus}

The particulars of treatment for IGCT in the basal ganglia or thalamus, including radiation and chemotherapy, are presented in Table 1.The mean age of the 20 patients with lesions in the basal ganglia or thalamus at the first hospital visit was 247.0 months (range, $95-783$ ), that of patients with IGCT was 246.2 months (range, 104-403), and that of patients with non-IGCT was 223.0 months (range, 95-783). The mean follow-up period was 76.0 months (range, 3-168) for all patients with lesions in the basal ganglia or thalamus, 85.2 months (range, 0 -168) for patients with IGCT, and 58.2 months (range, 3-163) for patients with non-IGCT. Ten of the 11 patients with IGCT in the basal ganglia or thalamus were men and 1 was a woman. Three of the 9 patients with non-IGCT in the basal ganglia or thalamus were men and 6 were women. For IGCT, the initial symptoms included hemiparesis $(n=3)$, psychological disorder $(n=1)$, and signs of increased intracranial pressure such as headache $(n=3)$, vomiting $(n=1)$, and diplopia $(n=5)$. Five of the 11 patients with IGCT had concomitant hydrocephalus at the initial visit. For non-IGCT, the initial symptoms included hemiparesis $(n=3)$, headache $(n=2)$, memory disturbance $(n=1)$, visual field impairment $(n=1)$, and seizure $(n=1)$, while 1 patient was asymptomatic (Table 2 ).

Three patients with IGCT in our cohort presented with multi-focal tumors.

\section{Histopathological findings of patients who underwent surgical intervention}

Seven of the 11 patients with IGCTs in the basal ganglia or thalamus underwent surgical intervention, and were diagnosed with germinomas based on histopathological examination (Table 1). The IGCTs of 3 patients (patients 1, 2, and 5) contained some degree of nongerminomatous germ cell tumor components, according to the value of other tumor markers such as HCG, HCG-beta and AFP. The histopathological diagnoses for the 9 non-IGCT cases were: 7 gliomas and 2 degenerative diseases. The histopathological findings of all patients are summarized in Table 1.

\section{Sensitivity and specificity of the PLAP value}

Each of the 11 patients with IGCTs in the basal ganglia or thalamus exhibited elevated levels of PLAP; with mean PLAP 1701.5 pg/mL (range, $10-8548 \mathrm{pg} / \mathrm{mL}$ ). In contrast, none of the patients with non-IGCTs in the basal ganglia or thalamus exhibited elevated PLAP value (Tables 2 ). Therefore, the sensitivity and specificity of PLAP determination were both calculated to be $100 \%$.

\section{Discussion}

Diagnosis of IGCT in the basal ganglia or thalamus remains a challenging task [6]. Basal ganglionic and thalamic lesions comprise heterogenous subsets of intracranial diseases including vascular and degenerative diseases, and some types of tumors [2]. They are relatively rare and have not been well characterized, thus complicating and prolonging the diagnostic process [6,16,10]. Unlike IGCTs in pineal and suprasellar regions, these heterogeneous and rare tumors are sometimes difficult to differentiate IGCT in the basal ganglia or thalamus from other diseases. In our case series, IGCTs accounted for 55\% (11 of 20 patients) of all the lesions in the basal ganglia or thalamus, besides vascular lesions. We observed that germinomas comprised the highest percentage of all IGCTs at this site.

IGCTs are divided into two categories: germinomas and non-germinomatous germ cell tumors (NGGCTs). NGGCTs include choriocarcinomas, embryonal carcinomas, teratomas (mature/immature), and yolk sac tumors [11]. These tumors may be single entities or heterogenous combinations of the above-mentioned tumor types, the latter of which are known as mixed germ cell tumors [11]. Pure germinomas and the germinomatous component of mixed germ cell tumors are undeniably sensitive to chemoradiotherapy, and are thus responsive to adjuvant 
therapy without surgical intervention; while some NGGCT components cannot be mitigated solely by chemoradiotherapy. Therefore, surgery is usually indicated for lesions that persist after chemoradiotherapy $[6,16,10]$. Thus, it is essential to determine whether the tumor is a pure germinoma, the most common type of IGCT, or if it contains a germinomatous component within the bulk of a mixed germ cell tumor, although no reliable marker is currently available for the detection of the chemoradiation-sensitive element [6].

The MRI characteristics of IGCTs in the basal ganglia or thalamus include heterogenous hypo- to iso-intensities on T1-weighted MRI and isoto hyperintensities on T2-weighted imaging $[1,17]$. Basal ganglionic IGCTs are predominantly located in the caput of the caudate nucleus adjacent to the anterior horn of the lateral ventricle and cause ipsilateral hemi-atrophy $[17,6,16,18,19]$. These tumors appear as ill-defined, slightly high densities on computed tomography $[16,10]$. Moreover, previous studies have reported the use of magnetic resonance spectroscopy, fluorodeoxyglucose-positron emission tomography (PET), ${ }^{11} \mathrm{C}$-methionine PET, and other neuroimaging modalities [1,20]. Although these methods are useful, they are not decisive [1,6]. The MRI findings of all our patients are presented in Figures 1 and 2.

Stereotactic biopsy is commonly used to confirm the histopathological diagnosis of these tumors [8]. Stereotactic biopsy is a well-established and point-accurate procedure for obtaining sample tissue from the target area [9]. Although this procedure is reportedly safe, the morbidity rate due to postoperative hemorrhage caused by injury to the perforating arteries or the highly vascular tumors is considered to be higher for tumors in the basal ganglia or thalamus compared with other regions $[9,21,8]$. In addition to the risk of complications, we emphasize that difficulties may occasionally be encountered in targeting the desired region due to the small lesion size and the presence of only subtle changes on T2-weighted/fluid-attenuated inversion recovery (FLAIR) imaging with faint-to-no enhancement on T1-weighted MRI, especially with IGCTs in the basal ganglia or thalamus $[9,22,16,20]$. In the present study, the lesions in patients GC1, GC2, and NGC 5 were hardly visible on T1-gadolinium enhanced MRI and could barely be identified as small lesions on FLAIR imaging (Figures 1, 2).

In contrast to biopsy, the measurement of the PLAP value in CSF provides a safe, simple, timely, and less invasive method to specifically detect the germinomatous component within IGCTs $[13,12,14]$. First, CSF examination for tumors in the basal ganglia or thalamus is not a new or additional method. In fact, CSF examination is required for differentiating among degenerative diseases such as MS, NMO, ADEM, and Behcet's disease, by measuring factors that are specific to each [23,3-5]. Moreover, the measurement of tumor markers such as HCG, HCGbeta, and AFP is well established and routine $[6,10,20]$. However, these markers can detect very limited subsets of IGCTs [11]. For instance, pure germinoma, the most common type of IGCT, rarely presents with an elevation of these tumor markers. The problem lies with the lack of a reliable marker for detecting the germinomatous component. Clinicians require information regarding the presence or absence of the germinomatous component in a tumor, because pure germinoma are responsive to chemoradiation therapy and do not require surgery, and chemoradiation can be expected to shrink the volume of the germinomatous component of mixed germ cell tumors. Neo-adjuvant therapy is applicable to these two subsets of IGCT, and surgery is indicated for the residual tumors [6]. The histopathological diagnosis of the biopsy or surgical resection specimen should be taken into consideration if the result of CSF examination is inconclusive or if the lesion continues to grow despite chemoradiotherapy. For instance, the PLAP value may not be elevated in tumors with only a mature teratoma component. The shrinkage of tumor volume cannot be expected after chemoradiation for such tumors; thus, surgical resection is recommended in the majority of cases (Figure 3).

The site of CSF aspiration in each case is shown in Table 1. In the present study, 5 CSF samples were taken from the ventricles in conjunction with treatment of existing hydrocephalus, while the others were aspirated via lumbar punctures. In our experience, considering the results from all PLAP assays, all patients with IGCT, and all brain regions, the PLAP values of samples taken by lumbar aspiration tend to be higher than those taken from ventricles, though we cannot show a significant difference at this point. Therefore, even if CSF samples are obtained from ventricles, we may recommend lumbar aspiration, if possible, after resolving a hydrocephalic state in cases of IGCT accompanied by hydrocephalus. Our data demonstrated that the sensitivity and specificity of PLAP measurements were both $100 \%$. The main objective of this study was to demonstrate the usefulness of measuring the value of PLAP in the CSF in cases of neoplasm at the basal ganglia or thalamic lesions; in these situations the lesion is isolated from the ventricular system and thus has no access to the CSF. The aforementioned results prove that the use of PLAP in CSF is feasible for differentiating the germinomatous component even in tumors in the basal ganglia or thalamus. Moreover, elevations of PLAP levels provide good evidence of a germinomatous element of some kind even if the lesion is barely visible on MRI. We admit that these results should be carefully discussed following the accumulation of evidence in the future studies. Nevertheless, we expect that the specificity and sensitivity of future PLAP measurements will be high based on the data obtained from our case series.

Furthermore, by determining PLAP levels serially, we can monitor the course of treatment in cases of IGCT and make a better-informed decision about subsequent treatment. In case GC5, for instance, the patient underwent lumbar puncture 9 times during the treatment. The initial CSF examination revealed high PLAP value $(6070 \mathrm{pg} / \mathrm{mL})$, which decreased to the level of $500 \mathrm{pg} / \mathrm{mL}$ after one course of chemotherapy. However, even though repeated chemotherapy treatments were administered, the value of PLAP showed no sign of decreasing, therefore, we selected radiation therapy as the next choice of treatment. Fortunately, the value of PLAP decreased to $19.0 \mathrm{pg} / \mathrm{mL}$ at the middle 
of radiation therapy and finally turned out negative after radiation therapy. It is true that it is expected for the tumor to shrink more in cases of IGCT with high PLAP value, though, the correlation between the tumor volume and PLAP value is still unknown.

Furthermore, the symptoms associated with lesions in the basal ganglia or thalamus are sometimes atypical and dissimilar compared to those associated with IGCTs in the pineal and suprasellar regions [22,18]. Diplopia, diabetes insipidus, etc., are the major symptoms of IGCTs of these regions, whereas psychological disorders, personality changes, involuntary movements, and sensory disturbances are occasionally observed in cases of IGCTs in the basal ganglia or thalamus [22,7,18-20]. This disparity prevents clinicians from recognizing the existence of tumors in the basal ganglia or thalamus in some cases, thereby delaying medical consultation or referral to the appropriate department for treating IGCTs in these anatomical regions [22]. The possible reasons for this include the complexity and invasiveness of the biopsy procedure required to differentiate IGCTs from other diseases. As already mentioned, it is sometimes difficult to approach the target for biopsy within a vaguely located tumor barely detected on MRI [22]. In contrast, the measurement of PLAP can be performed at any time or place, even in the outpatient department, and can facilitate an accurate diagnosis. Moreover, only a few days are required to obtain the PLAP value, whereas at least 1-2 weeks are required to obtain the histopathological diagnosis after biopsy. Therefore, PLAP measurement permits the early initiation of adjuvant therapy [7].

In addition to the complexity and difficulty in locating the target tissue for histological diagnosis for IGCTs in the basal ganglia or thalamus, how to decide on the optimal field for radiation therapy is still being debated owing to the inconspicuous and vague findings on MRI [24,2]. Generally, whole-brain irradiation or craniospinal irradiation is performed for basal ganglionic IGCTs $[24,16,2,10]$. Extended focal irradiation can be a treatment option, but there is an attendant risk with irradiating an insufficient area, because some IGCTs in the basal ganglia or thalamus can barely be identified on neuroimaging. In our case series, cerebrospinal irradiation was performed in 2 patients, whole-brain irradiation in 2, and whole-ventricle irradiation in 1, all with IGCTs in the basal ganglia, while whole-brain irradiation and whole-ventricle irradiation were performed in 1 and 4 patients, respectively, with IGCTs in the thalamus. The clinical information on radiation therapy was unavailable for one patient (patient GC6) owing to their transfer to another hospital. All patients with IGCT underwent cisplatin-based systemic chemotherapy. During our experience with treating IGCTs based on the PLAP value in a clinical setting, 1 patient succumbed to the primary disease and the others were recurrence-free during 85.2 months of follow-up.

A limitation of this study is the small number of patients included. In addition, the non-IGCT group in our case series included mainly glioma cases, followed by degenerative diseases and did not include other types of neoplasms such as metastatic brain tumor, lymphoma, and so on. Thus, further research is required to devise more optimal and adequate treatment strategies for cases of IGCTs in the basal ganglia or thalamus with collection of evidence from a greater number of relevant cases.

\section{Conclusion}

The PLAP value can specifically detect the germinomatous component of IGCTs in the basal ganglia or thalamus, similarly to IGCTs located along the midline. The measurement of PLAP can specifically differentiate the germinomatous component from other intracranial diseases promptly and less invasively. PLAP determination should be incorporated into the routine diagnostic approach. Biopsy or surgical resection for IGCTs should be considered only if the tumor markers are inconclusive or in the event of enlargement of the tumor volume or residual tumor even after the completion of treatment and with all tumor markers negative or nearly so.

\section{Declarations}

\section{Acknowledgements}

We are thankful to the staff of the Department of Pathology I of Tokyo Women's Medical University and Mr. Sakayori (pathological technician) for their assistance in preparing this manuscript.

\section{Funding}

This study was supported by research funds provided by the Department of Neurosurgery of Tokyo Women's Medical University.

\section{Conflict of interest/competing interests}

The authors declare that they have no conflicts of interest and competing interests.

\section{Statement of ethics}

The present study was approved by the Human Investigation Committee at our hospital and was performed in accordance with the Declaration of Helsinki. 
The institutional review board waived the requirement for informed consent, owing to the retrospective nature of the study. We removed all identifiers from our records upon completion of our study to protect patients' privacy.

\section{Availability of data and material}

Not applicable.

\section{Code availability}

Not applicable.

\section{Author contributions:}

Dr. Chiba wrote the manuscript with support from Dr. Aihara. Dr. Kawamata supervised this study.

\section{References}

1. Garcia-Santos JM, Torres del Rio S, Sanchez A, Martinez-Lage JF (2002) Basal ganglia and thalamic tumours: an imaging approximation. Childs Nerv Syst 18 (8):412-425. doi:10.1007/s00381-002-0606-Z

2. Villani A, Bouffet E, Blaser S, Millar BA, Hawkins C, Bartels U (2008) Inherent diagnostic and treatment challenges in germinoma of the basal ganglia: a case report and review of the literature. J Neurooncol 88 (3):309-314. doi:10.1007/s11060-008-9568-7

3. Howard J, Trevick S, Younger DS (2016) Epidemiology of Multiple Sclerosis. Neurol Clin 34 (4):919-939. doi:10.1016/j.ncl.2016.06.016

4. Oh J, Vidal-Jordana A, Montalban X (2018) Multiple sclerosis: clinical aspects. Curr Opin Neurol 31 (6):752-759. doi:10.1097/WC0.0000000000000622

5. Pohl D, Alper G, Van Haren K, Kornberg AJ, Lucchinetti CF, Tenembaum S, Belman AL (2016) Acute disseminated encephalomyelitis: Updates on an inflammatory CNS syndrome. Neurology 87 (9 Suppl 2):S38-45. doi:10.1212/WNL.0000000000002825

6. Fu W, Ju Y, Zhang S, You C (2017) Pediatric Basal Ganglia Region Tumors: Clinical and Radiologic Features Correlated with Histopathologic Findings. World Neurosurg 103:504-516. doi:10.1016/j.wneu.2017.04.004

7. Konovalov AN, Kadyrov SU, Tarasova EM, Mazerkina NA, Gorelyshev SK, Khukhlaeva EA, Kobyakov GL, Trunin YY, Sanakoeva AV, Kholodov BV, Shishkina LV, Panina TN, Ryzhova MV (2016) [Basal ganglia germinomas in children. Four clinical cases and a literature review]. Zh Vopr Neirokhir Im N N Burdenko 80 (1):71-82. doi:10.17116/neiro201680171-82

8. Sato S, Dan M, Hata H, Miyasaka K, Hanihara M, Shibahara I, Inoue Y, Kumabe T (2018) Safe Stereotactic Biopsy for Basal Ganglia Lesions: Avoiding Injury to the Basal Perforating Arteries. Stereotact Funct Neurosurg 96 (4):244-248. doi:10.1159/000492057

9. Nishihara M, Sasayama T, Kudo H, Kohmura E (2011) Morbidity of stereotactic biopsy for intracranial lesions. Kobe J Med Sci 56 (4):E148-153

10. Wang M, Zhou P, Zhang S, Liu X, Lv L, Wang Z, Ye F, Ju Y, Jiang S (2018) Clinical features, radiologic findings, and treatment of pediatric germ cell tumors involving the basal ganglia and thalamus: a retrospective series of 15 cases at a single center. Childs Nerv Syst 34 (3):423-430. doi:10.1007/s00381-017-3632-6

11. Takami H, Fukuoka K, Fukushima S, Nakamura T, Mukasa A, Saito N, Yanagisawa T, Nakamura H, Sugiyama K, Kanamori M, Tominaga T, Maehara T, Nakada M, Kanemura Y, Asai A, Takeshima H, Hirose Y, luchi T, Nagane M, Yoshimoto K, Matsumura A, Kurozumi K, Nakase H, Sakai K, Tokuyama T, Shibui S, Nakazato Y, Narita Y, Nishikawa R, Matsutani M, Ichimura K (2019) Integrated clinical, histopathological, and molecular data analysis of 190 central nervous system germ cell tumors from the iGCT Consortium. Neuro Oncol 21 (12):1565-1577. doi:10.1093/neuonc/noz139

12. Aihara Y, Watanabe S, Amano K, Komatsu K, Chiba K, Imanaka K, Hori T, Ohba T, Dairoku H, Okada Y, Kubo O, Kawamata T (2018) Placental alkaline phosphatase levels in cerebrospinal fluid can have a decisive role in the differential diagnosis of intracranial germ cell tumors. J Neurosurg:1-8. doi:10.3171/2018.3.JNS172520

13. Chiba K, Aihara Y, Komori T, Kawamata T (2020) Placental alkaline phosphatase in cerebrospinal fluid as a biomarker for optimizing surgical treatment strategies for pineal region germ cell tumors. Brain Tumor Pathol 37 (2):60-68. doi:10.1007/s10014-020-00364-0

14. Watanabe S, Aihara Y, Kikuno A, Sato T, Komoda T, Kubo O, Amano K, Okada Y, Koyamaishi Y (2012) A highly sensitive and specific chemiluminescent enzyme immunoassay for placental alkaline phosphatase in the cerebrospinal fluid of patients with intracranial germinomas. Pediatr Neurosurg 48 (3):141-145. doi:10.1159/000345632 
15. Okamoto M, Yamaguchi S, Ishi Y, Motegi H, Mori T, Hashimoto T, Terashita Y, Hirabayashi S, Sugiyama M, Iguchi A, Cho Y, Manabe A, Houkin K (2020) Diagnostic Capability of Cerebrospinal Fluid-Placental Alkaline Phosphatase Value in Intracranial Germ Cell Tumor. Oncology:1-9. doi:10.1159/000509395

16. Zhang S, Liang G, Ju Y, You C (2016) Clinical and Radiologic Features of Pediatric Basal Ganglia Germ Cell Tumors. World Neurosurg 95:516-524 e511. doi:10.1016/j.wneu.2016.08.072

17. Okamoto K, Ito J, Ishikawa K, Morii K, Yamada M, Takahashi N, Tokiguchi S, Furusawa T, Sakai K (2002) Atrophy of the basal ganglia as the initial diagnostic sign of germinoma in the basal ganglia. Neuroradiology 44 (5):389-394. doi:10.1007/s00234-001-0735-1

18. Tamaki N, Lin T, Shirataki K, Hosoda K, Kurata H, Matsumoto S, Ito H (1990) Germ cell tumors of the thalamus and the basal ganglia. Childs Nerv Syst 6 (1):3-7. doi:10.1007/BF00262257

19. Wong TT, Chen YW, Guo WY, Chang KP, Ho DM, Yen SH (2008) Germinoma involving the basal ganglia in children. Childs Nerv Syst 24 (1):71-78. doi:10.1007/s00381-007-0495-2

20. Sonoda Y, Kumabe T, Sugiyama S, Kanamori M, Yamashita Y, Saito R, Ariga H, Takai Y, Tominaga T (2008) Germ cell tumors in the basal ganglia: problems of early diagnosis and treatment. J Neurosurg Pediatr 2 (2):118-124. doi:10.3171/PED/2008/2/8/118

21. Farahmand D, Keil F, Gohring M, Dinc N, Seifert V, Marquardt G, Won SY, Quick-Weller J (2018) Prognostic risk factors for postoperative hemorrhage in stereotactic biopsies of lesions in the basal ganglia. Clin Neurol Neurosurg 174:180-184. doi:10.1016/j.clineuro.2018.09.008

22. Tso WW, Yung AW, Lau HY, Chan GC (2014) Basal ganglia germinoma: MRI classification correlates well with neurological and cognitive outcome. J Pediatr Hematol Oncol 36 (7):e443-447. doi:10.1097/MPH.0000000000000014

23. Borhani-Haghighi A, Kardeh B, Banerjee S, Yadollahikhales G, Safari A, Sahraian MA, Shapiro L (2019) Neuro-Behcet's disease: An update on diagnosis, differential diagnoses, and treatment. Mult Scler Relat Disord 39:101906. doi:10.1016/j.msard.2019.101906

24. Yeo KK, Kayser K, Margol AS, Wong KK, Robison N, Finlay J, Dhall G (2019) Clinical and neuropsychological outcome of pediatric nonmidline central nervous system germinoma treated with chemotherapy and reduced dose/volume irradiation: The Children's Hospital Los Angeles experience. Pediatr Blood Cancer 66 (12):e27983. doi:10.1002/pbc.27983

\section{Tables}

Table 1 Summary of surgical interventions, tumor markers (including PLAP, AFP, HCG, HCG-beta), and adjuvant therapies for 11 patients with IGCTs and 9 with non-IGCTs 


\begin{tabular}{|c|c|c|c|c|c|c|c|c|c|c|c|}
\hline Case & Hydrocephalus & $\begin{array}{l}\text { Surgical } \\
\text { intervention }\end{array}$ & Histopathology & $\begin{array}{l}\text { Site of } \\
\text { CSF } \\
\text { aspiration }\end{array}$ & PLAP & AFP & HCG & $\begin{array}{l}\text { HCG- } \\
\text { beta }\end{array}$ & RT field & $\begin{array}{l}\text { RT } \\
\text { dose } \\
\text { (Gy) }\end{array}$ & $\begin{array}{l}\text { CT [No. } \\
\text { of } \\
\text { courses] }\end{array}$ \\
\hline GC 1 & $(-)$ & $(-)$ & $(-)$ & $L+V$ & 426 & 1 & $<0.1$ & 0.2 & WBI & 25.2 & $\begin{array}{l}\text { CARE } \\
{[4]}\end{array}$ \\
\hline GC 2 & $(-)$ & $\begin{array}{l}\text { Stereotactic } \\
\text { biopsy }\end{array}$ & Germinoma & L & 100 & 1 & $<0.5$ & N/A & WVI & 25.2 & $\begin{array}{l}\text { CARE } \\
{[4]}\end{array}$ \\
\hline GC 3 & $(+)$ & $\begin{array}{l}\text { Craniotomy } \\
\text { (biopsy) }\end{array}$ & $\begin{array}{l}\text { Germinoma } \\
\text { with focal } \\
\text { STGC }\end{array}$ & L & 41 & 1 & 86.9 & 91 & WBI & 50.4 & $\begin{array}{l}\text { CARE } \\
{[1], \text { CCE }} \\
{[3]}\end{array}$ \\
\hline GC 4 & $(+)$ & $\begin{array}{l}\text { Endoscpic } \\
\text { biopsy }\end{array}$ & $\begin{array}{l}\text { Germinoma } \\
\text { with focal } \\
\text { STGC }\end{array}$ & V & 8548 & 38 & 20 & 105.9 & CSI & 50.4 & CCE [3] \\
\hline GC 5 & $(+)$ & $\begin{array}{l}\text { Endoscpic } \\
\text { biopsy }\end{array}$ & Germinoma & V & 6070 & $<1$ & 691.4 & 808.7 & CSI & 50.4 & $\begin{array}{l}\text { ICE [4], } \\
\text { CCE [2] }\end{array}$ \\
\hline GC 6 & $(-)$ & $\begin{array}{l}\text { Stereotactic } \\
\text { biopsy }\end{array}$ & Germinoma & L & 10 & 1 & 0.2 & 0.2 & N/A & $\mathrm{N} / \mathrm{A}$ & $\mathrm{N} / \mathrm{A}$ \\
\hline GC 7 & $(-)$ & $(-)$ & $(-)$ & L & 104 & 2 & $<0.5$ & $<0.5$ & WVI & 25.2 & $\begin{array}{l}\text { CARE } \\
{[4]}\end{array}$ \\
\hline GC 8 & $(+)$ & $(-)$ & $(-)$ & L & 561 & 1 & 1.2 & 3 & WVI & 25.2 & $\begin{array}{l}\text { CARE } \\
{[4]}\end{array}$ \\
\hline GC 9 & $(+)$ & $\begin{array}{l}\text { Stereotactic } \\
\text { biopsy }\end{array}$ & Germinoma & L & 1070 & 1 & $<0.1$ & 4.6 & WBI & 30.6 & $\begin{array}{l}\text { CARE } \\
{[4]}\end{array}$ \\
\hline $\begin{array}{l}\mathrm{GC} \\
10\end{array}$ & $(-)$ & $(-)$ & $(-)$ & L & 1601 & $<1$ & $\mathrm{~N} / \mathrm{A}$ & 0.5 & WVI & 25.2 & $\begin{array}{l}\text { CARE } \\
{[4]}\end{array}$ \\
\hline $\begin{array}{l}\text { GC } \\
11\end{array}$ & $(-)$ & $\begin{array}{l}\text { Craniotomy } \\
\text { (biopsy) }\end{array}$ & Germinoma & L & 186 & 4 & $<0.5$ & $<0.5$ & WVI & 25.2 & $\begin{array}{l}\text { CARE } \\
{[4]}\end{array}$ \\
\hline $\begin{array}{l}\text { NGC } \\
1\end{array}$ & $(-)$ & $\begin{array}{l}\text { Stereotactic } \\
\text { biopsy }\end{array}$ & Glioma (AA) & L & $<8.0$ & $<1$ & $<0.5$ & $<0.5$ & $\begin{array}{l}\text { Extended } \\
\text { focal }\end{array}$ & 54 & ACNU \\
\hline $\begin{array}{l}\text { NGC } \\
2\end{array}$ & $(+)$ & Resection & $\begin{array}{l}\text { Diffuse midline } \\
\text { glioma, } \\
\text { H3K27M } \\
\text { mutant }\end{array}$ & L & $<8.0$ & $<1$ & $<1.0$ & $<0.5$ & $\begin{array}{l}\text { Extended } \\
\text { focal }\end{array}$ & 54 & TMZ \\
\hline $\begin{array}{l}\text { NGC } \\
3\end{array}$ & $(-)$ & $\begin{array}{l}\text { Stereotactic } \\
\text { biopsy }\end{array}$ & MS & L & $\begin{array}{l}<8.0 \\
{[0.2]}\end{array}$ & N/A & $\mathrm{N} / \mathrm{A}$ & $\mathrm{N} / \mathrm{A}$ & $(-)$ & $(-)$ & $(-)$ \\
\hline $\begin{array}{l}\text { NGC } \\
4\end{array}$ & $(+)$ & Resection & Glioma & V & $\begin{array}{l}<8.0 \\
{[1]}\end{array}$ & 3 & $<0.1$ & $<0.1$ & $\begin{array}{l}\text { Extended } \\
\text { focal }\end{array}$ & 45 & $(-)$ \\
\hline $\begin{array}{l}\text { NGC } \\
5\end{array}$ & $(-)$ & $\begin{array}{l}\text { Stereotactic } \\
\text { biopsy }\end{array}$ & $\begin{array}{l}\text { Anti-MOG } \\
\text { antibody- } \\
\text { associated } \\
\text { diseases }\end{array}$ & L & $<8.0$ & $<1$ & $<1.0$ & $<0.5$ & $(-)$ & $(-)$ & $(-)$ \\
\hline $\begin{array}{l}\text { NGC } \\
6\end{array}$ & $(+)$ & Resection & Glioma (GBM) & L & $\begin{array}{l}<8.0 \\
{[4.7]}\end{array}$ & 1 & NA & 0.4 & $\begin{array}{l}\text { Extended } \\
\text { focal }\end{array}$ & 50.4 & TMZ \\
\hline $\begin{array}{l}\text { NGC } \\
7\end{array}$ & $(+)$ & $\begin{array}{l}\text { Stereotactic } \\
\text { biopsy }\end{array}$ & Glioma (OA) & L & $\begin{array}{l}<8.0 \\
{[0.5]}\end{array}$ & 1 & NA & 0.5 & $(-)$ & $(-)$ & $(-)$ \\
\hline $\begin{array}{l}\text { NGC } \\
8\end{array}$ & $(+)$ & Resection & $\begin{array}{l}\text { Diffuse midline } \\
\text { glioma, } \\
\text { H3K27M } \\
\text { mutant }\end{array}$ & V & $<8.0$ & $<1$ & $<1.0$ & 1 & $\begin{array}{l}\text { Extended } \\
\text { focal }\end{array}$ & 60 & TMZ \\
\hline $\begin{array}{l}\text { NGC } \\
9\end{array}$ & $(+)$ & Resection & Glioma (AO) & L & $<8.0$ & 1 & 0.1 & $<0.1$ & $(-)$ & $(-)$ & $(-)$ \\
\hline
\end{tabular}

Abbreviations: IGCT: intracranial germ cell tumors; GC, patient with germ cell tumor; STGC, syncytiotorophoblastic giant cell; CSF, cerebrospinal fluid; L, lumbar; V, ventricle; PLAP, placental alkaline phosphatase; AFP, alpha-fetoprotein; HCG, human chorionic gonadotropin; $\mathrm{RT}$, radiation therapy; WBI, whole brain irradiation; WVI, whole ventricle irradiation; CSI, cerebro-spinal irradiation; N/A, not available; Gy, gray; No., number; CT, chemotherapy; NGC, patients with non-germ cell tumor; AA, anaplastic astrocytoma; H3K27M, histone 3 K 27 M; MS, multiple 
sclerosis; GBM, glioblastoma; OA, oligo-astrocytoma; AO, anaplastic oligodendroglioma; ACNU, nimustine hydrochloride; TMZ, temozolomide. The chemotherapy regimens were as follows: CARE, carboplatin and etoposide; CCE, cyclophosphamide, carboplatin, and etoposide; ICE, ifosfamide, carboplatin, and etoposide

Table 2 Characteristics and clinical courses of 11 patients with IGCTs and 9 patients with non-IGCTs. Abbreviations: GC, patient with germ cell tumor; NGC, patients with non-germ cell tumor; M, male; F, female; No., number; BG, basal ganglia; HA, headache; NA, nausea; N/A, not available

\begin{tabular}{|c|c|c|c|c|c|c|c|c|}
\hline Case & Age & Gender & $\begin{array}{l}\text { No. of } \\
\text { lesion }\end{array}$ & Location & Initial symptoms & $\begin{array}{l}\text { Period from onset } \\
\text { to initial visit } \\
\text { (months) }\end{array}$ & $\begin{array}{l}\text { Follow-up } \\
\text { period } \\
\text { (months) }\end{array}$ & Prognosis \\
\hline GC 1 & 8 & M & Single & Parasellar, BG & Hemiparesis & 9 & 124 & Alive \\
\hline GC 2 & 12 & $\mathrm{~F}$ & Multiple & Parasellar, BG & Hemiparesis & 3 & 168 & Alive \\
\hline GC 3 & 13 & M & Single & BG & Hemiparesis & 1 & 34 & Dead \\
\hline GC 4 & 14 & M & Single & $B G$ & $\mathrm{HA}$ & 6 & 112 & Alive \\
\hline GC 5 & 18 & M & Multiple & Cerebellum, BG & HA, NA, vomit & 5 & 69 & Alive \\
\hline GC 6 & 19 & M & Multiple & $\begin{array}{l}\text { Midbrain, } \\
\text { thalamus }\end{array}$ & diplopia & 0 & 0 & Alive \\
\hline GC 7 & 20 & M & Single & Thalamus & diplopia & 5 & 32 & Alive \\
\hline GC 8 & 25 & M & Single & Thalamus & diplopia & 0 & 140 & Alive \\
\hline GC 9 & 29 & M & Single & Thalamus & Psycho, HA & 99 & 122 & Alive \\
\hline $\begin{array}{l}\text { GC } \\
10\end{array}$ & 31 & M & Single & Thalamus & diplopia & 0 & 53 & Alive \\
\hline $\begin{array}{l}\text { GC } \\
11\end{array}$ & 34 & M & Single & Thalamus & diplopia & 0 & 83 & Alive \\
\hline $\begin{array}{l}\text { NGC } \\
1\end{array}$ & 9 & $\mathrm{~F}$ & Single & $B G$ & Asymptomatic & 0 & 62 & Alive \\
\hline $\begin{array}{l}\text { NGC } \\
2\end{array}$ & 10 & $M$ & Single & thalamus & Hemiparesis & 1 & 3 & Alive \\
\hline $\begin{array}{l}\text { NGC } \\
3\end{array}$ & 11 & $\mathrm{~F}$ & Single & thalamus & Hemiparesis & 1 & 125 & Alive \\
\hline $\begin{array}{l}\text { NGC } \\
4\end{array}$ & 15 & M & Single & thalamus & $\mathrm{HA}$ & 0 & 127 & Alive \\
\hline $\begin{array}{l}\text { NGC } \\
5\end{array}$ & 15 & $\mathrm{~F}$ & Single & $B G$ & $\mathrm{HA}$ & 0 & 21 & Alive \\
\hline $\begin{array}{l}\text { NGC } \\
6\end{array}$ & 17 & $\mathrm{~F}$ & Single & thalamus & Visual disturbance & 0 & 8 & Dead \\
\hline $\begin{array}{l}\text { NGC } \\
7\end{array}$ & 17 & M & Single & thalamus & Seizure & $\mathrm{N} / \mathrm{A}$ & 163 & Alive \\
\hline $\begin{array}{l}\text { NGC } \\
8\end{array}$ & 33 & $\mathrm{~F}$ & Single & thalamus & Hemiparesis & 0 & 6 & Alive \\
\hline $\begin{array}{l}\text { NGC } \\
9\end{array}$ & 65 & $\mathrm{~F}$ & Single & thalamus & $\begin{array}{l}\text { Memory } \\
\text { disturbance }\end{array}$ & 12 & 67 & Dead \\
\hline
\end{tabular}

IGCT: intracranial germ cell tumors

\section{Figures}



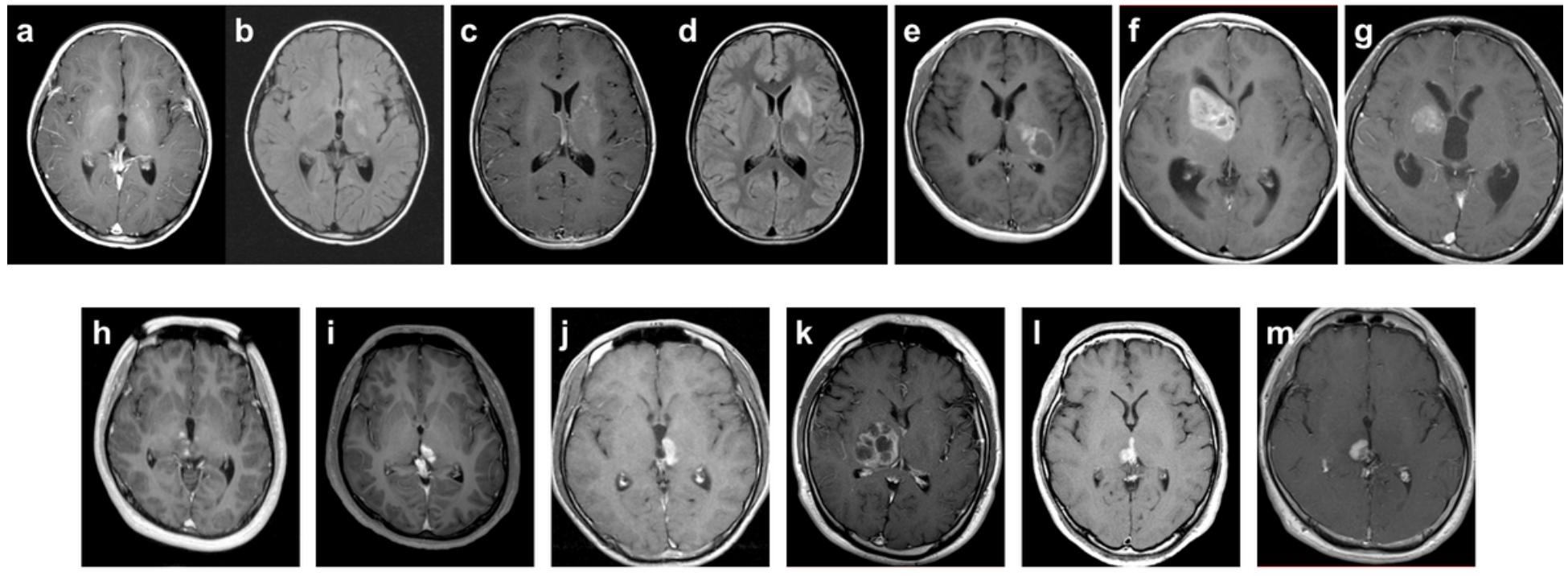

Figure 1

The MRI series of our 11 patients with IGCTs a, T1-gadolinium (Gd); b, FLAIR in GC 1; c, T1-Gd; d, FLAIR in GC 2; e, T1-Gd in GC3; f, T1-Gd in GC 4; g, T1-Gd in GC 5; h, T1-Gd in GC 6; i, T1-Gd in GC 7; j, T1-Gd in GC 8; k, T1-Gd in GC 9; I, T1-Gd in GC 10; m, T1-Gd in GC 11 Abbreviations: $\mathrm{MRI}$, magnetic resonance imaging; IGCT, intracranial germ cell tumors; FLAIR, fluid-attenuated inversion recovery; GC, patient with germ cell tumor.
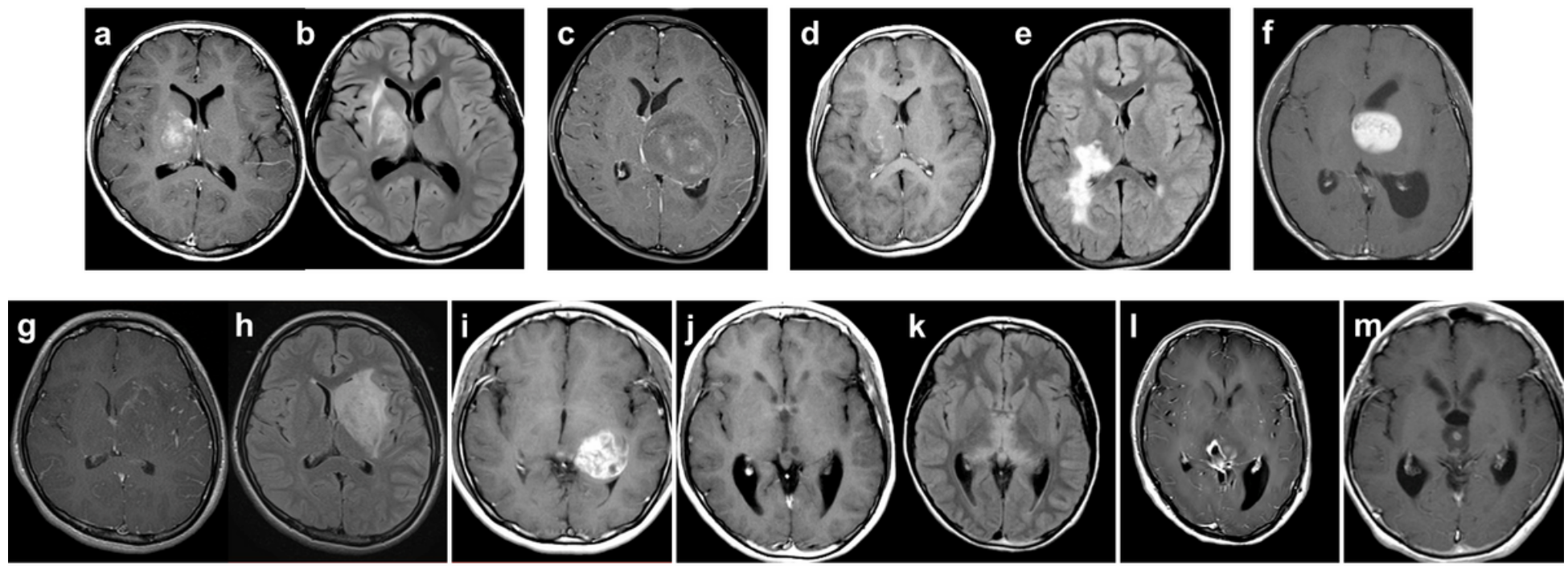

Figure 2

The MRI series of our 9 patients with non-IGCTs a, T1-gadolinium (Gd); b, FLAIR in NGC 1; c, T1-Gd in NGC 2; d, T1-Gd; e, FLAIR in NGC 3; f, T1Gd in NGC4; g, T1-Gd; h, FLAIR in NGC 5; i, T1-Gd in GC 6; j, T1-Gd; k, FLAIR in GC 7; I, T1-Gd in GC 8; m, T1-Gd in GC 9 Abbreviations: MRI, magnetic resonance imaging; IGCT, intracranial germ cell tumors; FLAIR, fluid-attenuated inversion recovery; GC, patient with non-germ cell tumor. 


\section{Germ cell tumors in the basal ganglia and thalamus}

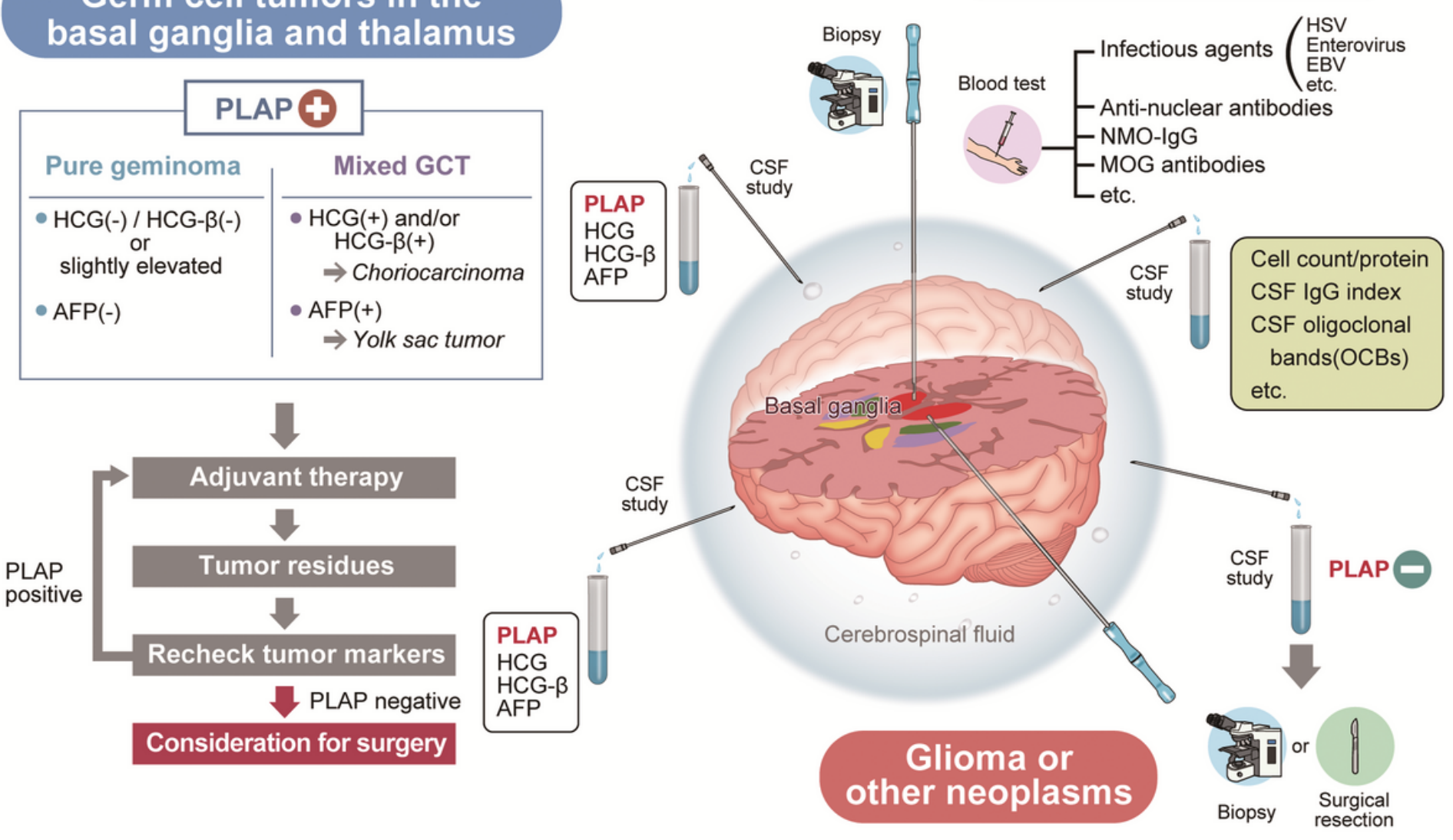

\section{Degenerative diseases}

\section{Figure 3}

Schematic diagram for the differential diagnosis process of lesions in the basal ganglia or thalamus. PLAP, placental alkaline phosphatase; HCG, human chorionic gonadotropin; AFP, alpha-fetoprotein; GCT, germ cell tumor; CSF, cerebrospinal fluid; HSV, Herpes simplex virus; EBV, Epstein-Barr virus; etc., etcetera; NMO-IgG, Neuromyelitis Optica- immunoglobulin G; MOG, myelin-oligodendrocyte glycoprotein. 